\title{
La doctrina Obama: un análisis del discurso de El Cairo
}

\author{
Peter Murphy Lewis*
}

The convictions that leaders have formed before reaching high office are the intellectual capital they will consume as long as they continue in office.

Henry Kissinger - 1979

The social function of science vis-a-vis ideologies is first to understand what they are, how they work, what gives rise to them and second to criticize them, to force them to come to terms with (but not necessarily to surrender to) reality.

Desde la academia, existe una tendencia a encasillar a nuestros líderes políticos dentro de un paradigma basado en un análisis de su cosmovisión, manifestada principalmente por medio de sus palabras y acciones. El presidente Obama no solo no podrá eludir esta tendencia sino que pareció compartirla con sabiduría al elegir las palabras de su publicitado discurso del 4 de junio en la universidad de El Cairo. En 50 minutos y 6,000 palabras logró ser comparado con el presidente Kennedy, en su discurso de Berlín, de 1963. La reacción mundial fue innegablemente eufórica, incluso dentro de algunos círculos de Hamas. Surge entonces la pregunta de si estamos ante una nueva doctrina de Obama en materia de política exterior y para responderla es preciso releer sus palabras desde una verstehen weberiana.

Fred Greenstein, profesor de Princeton, construyó una carrera de 50 años analizando a los presidentes de Estados Unidos bajo un microscopio

"Académico del Instituto de Estudios Internacionales.<pmlewis@uchile.cl>. 
psicológico. ${ }^{1}$ El ejercicio es eficaz en la medida en que nos ayuda a crear un sentido coherente de las diferentes políticas exteriores. Por lo general no se podrá construir una visión acertada si no se cuenta con una distancia suficiente en el tiempo, puesto que los presidentes no suelen manifestar sus criterios hasta que sobrevienen crisis. Y, por cierto, Obama enfrenta varias crisis, incluyendo la crisis financiera, los dos conflictos de Irak y Afganistán y un creciente problema de seguridad en Pakistán y Corea del Norte, por no mencionar el terrorismo, tema que aún dista mucho de resolverse.

Poco importa la visión del mundo de un presidente si ella no ejerce ninguna influencia efectiva, si no trae consecuencias reales. Ricard Neustadt, en su libro de 1960, destaca tres fuentes de poder efectivo:

In short, his power is the product of his vantage points in government, together with his reputation in the Washington community and his prestige outside ${ }^{2}$.

No se puede subestimar la ventajosa posición de Obama en 2009, dado su amplia popularidad tanto en el país

1 En su versión actualizada, su obra incluye a Obama. The Presidential Difference: Leadership Style from FDR to Barak Obama, 2009, 3a. ed., Princeton University Press.

2 Presidential Power and the Modern President: the politics of leadership from Roosevelt to Reagan (1990), Nueva York, Free Press, p. 150 como en el exterior. Además, el amplio apoyo de que goza se ha visto fortalecido por el rechazo a la doctrina Bush. ${ }^{3}$

El autor James David Barber puso de relieve las mismas fuentes de influencia en Presidential Power and the Modern President (1972), pero destacó la importancia del carácter del presidente, los rasgos de su personalidad que son moldeados desde la infancia. ${ }^{4}$ En su clasificación tradicional, Barber probablemente diría que Obama tiene un carácter "activo-positivo,» esto es, el que corresponde a quienes pueden resolver problemas sanamente, es decir adaptándose al contexto que se enfrentan.

Neustadt va más lejos:

A President, himself, affects the flow of power from these sources, though whether they flow freely or run dry he never will decide alone. He makes his personal impact by the things he says and does. Accordingly, his choices of what he should say and do, and how and when, are his means to conserve and tap the sources of his power ${ }^{5}$.

3 Jervis, Robert, «Understanding the Bush Doctrine", Political Science Quarterly, Volume 118, No 3, Fall 2003, pp. 365388(24)

4 Barber, James David (1972), The Presidential Character, Englewood Cliffs, NJ:, Prentice-Hall. Para otro texto fundamental sobre presidentes y personalidad, véase también George, Alexander L., «Assessing Presidential Character», World Politics, 26 (enero 1974) pp. 234-282.

Ibidem, p. 150. 
En el discurso pronunciado en Egipto Obama nos mostró su visión del mundo cuando optó por utilizar su capital político como líder carismático en el frente internacional. Al momento de analizar el discurso de Obama el cómo y el cuándo son decisivos. El tono del nuevo presidente fue drásticamente diferente del de Bush, que podría describirse como dicotómico y amenazador. Aún es pronto para afirmar que este nuevo tono coincide con una política nueva aplicada a los hechos, ya que hasta el momento no se han establecido grandes diferencias con su predecesor en las guerras de Irak y Afganistán.

El lugar elegido para el discurso es importante en cuanto Obama busca ayudar a Egipto a resposicionarse en su estatus de poder predominante en el mundo árabe. Egipto desempeña un papel clave entre los intereses nacionales de Estados Unidos -específicamente en el conflicto palestino-israelí- debido a que es el país árabe más poblado y constituye un centro cultural y académico de importancia.

Egipto sigue siendo el segundo mayor receptor de ayuda militar estadounidense y aunque el presidente Obama esté en desacuerdo con el régimen dictatorial del presidente Hosni Mubarak, no se arriesgaría a aislar a un aliado tan esencial.

El momento elegido no fue más aleatorio que el lugar. En el frente internacional, la luna de miel de Obama aún no ha concluido.. Consciente de ello, Obama utiliza su encanto personal para dar un nuevo tono a las relacio- nes entre Estados Unidos y el mundo árabe-islámico. El discurso de Obama puso particular énfasis en los temas de democracia, extremismo y armas nucleares justo ocho días antes de las elecciones en Irán.

Antes del discurso, la Casa Blanca utilizó todo su aparataje comunicacional para inyectar en los medios el mensaje de un nuevo comienzo del partnership entre ambas partes. Por ser el primer presidente de Estados Unidos con relaciones familiares directas con el Islam, se presentó con su nombre completo, «Barak Hussein Obama,» lo que le brinda una ventaja a nivel internacional que genera sombras en su campaña interna. Obama representa el mestizaje racial y la confluencia de diversas creencias religiosas, y encarna la esperanza de relacionarse con millones de musulmanes, tanto árabes como persas y asiáticos, que comparten su diversidad. Estas semejanzas fueron lo que llevó a Obama a descartar los estereotipos mutuos basados en religión y etnicidad. Es decir, Obama fue capaz de diferenciarse del impopular Bush incluso antes de iniciar su discurso.

El contenido del discurso del 4 de junio fue directo: primero, respecto de Estados Unidos para el Islam y los países musulmanes; segundo, en cuanto a la cooperación entre iguales; tercero, en el análisis de los temas críticos para el mundo islámico. Sus palabras fueron elegidas cuidadosamente para dejar en claro que la invasión al Afganistán fue necesaria y la de Irak una decisión. Utilizó nueve veces la palabra «ex- 
tremismo» para describir lo que los estadounidenses llaman «terrorismo,» concepto que omitió deliberadamente dada su fuerte carga ideológica. Al mismo tiempo, Obama intentó mostrar que el extremismo es una amenaza para la humanidad. Solo ocupó la palabra «AlQueda» en tres ocasiones, pero en cambio en 10 y 15 oportunidades, respectivamente, usó las palabras «respeto» y «paz». Lo más importante es que Obama evitó la dicotomía entre tiranía y libertad y optó por un término culturalmente más sensible como «justicia,» con lo cual acepta que un dictador benevolente no es una paradoja para el mundo islámico.

Antes del discurso, en el partido Republicano y en el lobby israelí de Washington surgieron temores de que Obama ajustara la política exterior de Estados Unidos hacia Irán debilitando la alianza con Israel. En definitiva, Obama reorientó el debate palestino-israelí al plantearlo como un futuro entre dos Estados independientes y soberanos. No obstante, afirmó que los lazos entre Estados Unidos e Israel son indestructibles, palabra que deja poco margen a la interpretación. Los reformistas que promueven la democracia en el mundo musulmán fueron los menos satisfechos con el discurso. No hubo condenas a los gobiernos autoritarios de la región, lo que podría leerse como una postura pragmática de Obama respecto de los posibles cambios. Por la misma razón, poco dijo sobre Pakistán debido a que no ofrece novedades respecto de la política de Bush en esta materia. En su favor, hay que decir que Obama no tuvo los típicos gestos simbólicos de apoyo a los líderes autoritarios locales, como grandes halagos o demostraciones de afecto. Sin embargo, ello es poco consuelo para los más moderados, que buscan mayor libertad y democracia.

Se ha aludido a una doctrina de Obama en términos de "promoción de la dignidad», concepto que es más bien idealista. Los críticos sostienen que esa doctrina poco tiene de novedoso y que constituye un cambio meramente semántico a partir de la promoción de la democracia de Bush. El discurso de El Cairo desafía cualquier paralelismo entre la política exterior de Bush y la de Obama, a pesar de que ambos insisten en que hay que aumentar el envío de tropas a Afganistán.

Aun así, hay que considerar que los principales medios de Obama para concretar los intereses nacionales de los Estados Unidos son la diplomacia y el consenso internacional.. El nombramiento de Hillary Clinton como Secretaria de Estado lo confirma, así como la continua búsqueda de comunicación directa con actores internacionales como Irán, Rusia y China.

Desafortunadamente para los académicos, Obama sigue desafiando las definiciones en función del encasillamiento de su política exterior como una ideología identificable. Ninguna de las antiguas etiquetas «dovish» o «hawkish» satisface.

Sin mayores explicaciones, todo el discurso entero de Obama puede resumirse con sus propias palabras: 
[We] seek - a world where extremists no longer threaten our people, and American troops have come home; a world where Israelis and Palestinians are each secure in a state of their own, and nuclear energy is used for peaceful purposes; a world where governments serve their citizens, and the rights of all God's children are respected. Those are mutual interests. That is the world we seek. But we can only achieve it together.

No cabe duda que este resumen no es suficiente, puesto que al analizar las ideas que subyacen el discurso habrá que tener presentes la elección del tiempo, el lugar, las palabras y el contexto en que se pronunciaron. Deberán enten- derse como una plataforma multifacética de la política exterior mediante la cual el nuevo presidente de los Estados Unidos piensa interactuar con el mundo musulmán, si no como su visión de la cooperación en el mundo actual. El tono y contexto del discurso contienen algo de amor fraternal, un par de excusas indirectas y algunas metas utópicas de cooperación. Encasillar a Obama en un paradigma requiere más de una lectura de este discurso trascendente. Es más, para completar el estudio profundo de la ideología que tantos académicos han estado buscando durante años, será preciso observar los hechos y la materialización de las palabras. 